\title{
Drug Delivery Properties of Macroporous Polystyrene Solid Foams
}

\author{
C. Canal ${ }^{\mathrm{a}, \mathrm{c}, \mathrm{d}}$, R.M. Aparicio ${ }^{\mathrm{a}, \mathrm{c}}$, A. Vílchez ${ }^{\mathrm{b}, \mathrm{c}}$, J. Esquena $^{\mathrm{b}, \mathrm{c}}$, M.J. García-Celma ${ }^{\mathrm{a}, \mathrm{c}, *}$ \\ a Pharmacy and Pharmaceutical Technology Dpt., R+D Associated Unit to CSIC, Faculty of Pharmacy, University of \\ Barcelona (UB), Joan XXIII s/n, Barcelona, Spain. \\ ${ }^{\mathrm{b}}$ Institute for Advanced Chemistry of Catalonia, Consejo Superior de Investigaciones Científicas (IQAC-CSIC), Jordi \\ Girona, 18-26, 08034 Barcelona, Spain. \\ ${ }^{\mathrm{c}}$ CIBER de Bioingeniería, Biomateriales y Nanomedicina (CIBER-BBN), Jordi Girona, 18-26, 08034 Barcelona. \\ ${ }^{\mathrm{d}}$ Biomaterials, Biomechanics and Tissue Engineering Group, Materials Science and Metallurgy Dpt., Technical \\ University of Catalonia, Avda. Diagonal 647, Barcelona, Spain.
}

Received, February 17, 2011; Revised, August 24, 2011; Accepted, January 21, 2012; Published, January 30, 2012.

\begin{abstract}
Purpose. Polymeric porous foams have been evaluated as possible new pharmaceutical dosage forms. Methods. These materials were obtained by polymerization in the continuous phase of highly concentrated emulsions prepared by the phase inversion temperature method. Their porosity, specific surface and surface topography were characterized, and the incorporation and release of active principles was studied using ketoprofen as model lipophilic molecule. Results. Solid foams with very high pore volume, mainly inside macropores, were obtained by this method. The pore morphology of the materials was characterized, and very rough topography was observed, which contributed to their nearly superhydrophobic properties. These solid foams could be used as delivery systems for active principles with pharmaceutical interest, and in the present work ketoprofen was used as a model lipophilic molecule. Conclusions. Drug incorporation and release was studied from solid foam disks, using different concentrations of the loading solutions, achieving a delayed release with short lag-time.
\end{abstract}

This article is open to POST-PUBLICATION REVIEW. Registered readers (see "For Readers") may comment by clicking on ABSTRACT on the issue's contents page.

\section{INTRODUCTION}

Foams (understood as coarse dispersions of gas bubbles in liquids) find applications in pharmacy as aqueous and non-aqueous spray preparations for topical, rectal and vaginal medications and for burn dressings. Because of their high interfacial area and relatively high interfacial tension, foams are unstable in the thermodynamic sense $(1,2)$. On another hand, solid foams are stable, can be prepared from many different materials (polymers, ceramics, metals and their composites) and have been studied for their potential use as implants in tissue engineering applications. As illustration, several patents and articles (3-9) have described biopolymer or calcium phosphate foams for tissue repair and reconstruction containing collagen and calcium phosphate, hydroxyapatite or demineralized bone. Other examples include collagen foams used as hemostatic agents (10), scaffolds for tissue repair (11), and supports for cell growth (12). Recently, three-dimensional scaffolds have been designed to mimic boneforming characteristics of autografts, such as chemical composition $(13,14)$ or microstructure $(15,16)$, in order to facilitate vascularization in the material and provide a suitable environment for bone formation (13-16).

Porous materials constitute an integral part of various dosage forms (17). The porous network is important in determining both natural and practical applications such as dissolution, adsorption and diffusion of drugs (18). In recent years, the use of mesoporous materials for hosting and further delivering of a variety of molecules of pharmaceutical interest has been described (19, 20). It has been shown that both small and large molecules can be entrapped within the mesopores by an impregnation process and released via a diffusion-controlled mechanism (21). In this context, porous materials may have several attractive features, such as high surface areas, tunable pore sizes with narrow distributions and well-defined surface properties, thus allowing the adsorption and release of certain kinds of drugs in a more reproducible and predictable manner (22).

Corresponding Author: M.J. García-Celma; Pharmacy and Pharmaceutical Technology Dpt., R+D Associated Unit to CSIC, Faculty of Pharmacy, University of Barcelona (UB), Avda. Joan XXIII s/n, 08028 Diagonal 647 Barcelona, Spain. Email: mjgarcia@ub.edu 
Porous materials are well known for a variety of uses, from molecular sieves to catalysis (23, $24)$, and the introduction of pores in the range from macro $(>50 \mathrm{~nm})$, meso $(2-50 \mathrm{~nm})$ and micro $(<2 \mathrm{~nm})$, in an ordered way, is important for specific applications. Most synthetic methods to produce hierarchical porous structures are laborious multi-step processes and consequently simple methods are of interest (25). For instance, polystyrene (PS) solid foams have traditionally been prepared by extrusion with a blowing agent or by expansion of polystyrene beads, and consequently these porous foams are often made of closed macropores (not interconnected) with limited absorption and release properties. They are generally used as packaging materials, as insulating materials (26) or for heavy metal removal from industrial effluents (27).

As an alternative for conventional methods for preparing solid foams, emulsions can be used as templates for producing either particles or porous scaffolds when selecting the disperse phase of the emulsion or the continuous phase for polymerization $(25,28)$. The polymerization of the continuous phase of a highly concentrated emulsion, followed by the removal of the internal phase, leads to the formation of solid foams with very high pore volume $(29,30)$. For instance, solid polystyrene foams, with very large pore volumes $(\geq 15 \mathrm{~mL} / \mathrm{g})$ have been prepared with a relatively narrow pore size distribution. Such foams have been obtained by polymerization in the continuous phase of highly concentrated water-in-styrene emulsions stabilized by nonionic surfactants. These emulsions can be prepared by a method based on the phase inversion temperature (PIT) (31). Low-energy emulsification methods like PIT, make use of the phase transitions taking place during the emulsification process to produce highly concentrated emulsions almost spontaneously (32-34). PIT method is based on solubility changes, with temperature, of polyoxyethylene-type nonionic surfactants. These surfactants become more lipophilic with increasing temperature due to dehydration of the polyoxyethylene chains. At low temperature, the surfactant monolayer has a large positive spontaneous curvature forming oil- swollen micellar solutions $(\mathrm{O} / \mathrm{W}$ microemulsions) which may coexist with an excess oil phase dispersed as $\mathrm{O} / \mathrm{W}$ emulsion droplets. At high temperatures, the spontaneous curvature becomes negative and water-swollen reverse micelles (W/O microemulsions) coexist with excess water phase, leading to $\mathrm{W} / \mathrm{O}$ emulsions. There is an intermediate temperature (the HLB temperature), where the spontaneous curvature becomes close to zero and a bicontinuous microemulsion, D phase, containing comparable amounts of water and oil, coexists with both excess water and oil phases (31). The PIT emulsification method takes advantage of the extremely low interfacial tensions achieved at the HLB temperature (31), to promote emulsification. However, coalescence rate at the HLB temperature is rather fast and the emulsions are very unstable, although emulsification is favored. This problem is overcome by rapidly changing the temperature (by about $25-30^{\circ} \mathrm{C}$ ) of emulsions prepared at the HLB temperature. Rapid cooling or heating allows to obtain kinetically stable emulsions $(\mathrm{O} / \mathrm{W}$ or $\mathrm{W} / \mathrm{O}$, respectively) with very small droplet size and narrow size distribution (34).

By polymerization of one or more monomers in the external phase of such emulsions, PS macroporous foams could be obtained with controlled pore morphology and although this polymer is not biocompatible, the study of its drug delivery properties obtained could serve as a model for future works.

The porous structure of solid foams prepared from highly concentrated emulsions, somehow mimicking the inner bone structure, suggests biomedical applications, such as implants or prostheses, and consequently the solid foams could be used as vehicles for therapeutic agents. Although application of biomaterials has been one of the major assets in modern medicine to improve the quality of life of patients, there are still several issues to be improved. For instance, occurrence of biomaterial related infections is still a serious health threat to the individual patient, and to avoid systemic antibiotic administration, local drug delivery systems are under study (35). Another issue to be addressed in biomaterials is enhancing healing conditions after implantation, and limiting or avoiding inflammatory processes could be an interesting achievement.

Drugs with small molecular weight that control proliferation or differentiation of cells have been incorporated into biodegradable scaffolds to induce cellular differentiation and tissue remodeling. For example, dexamethasone, a steroidal anti-inflammatory drug, was loaded into the inner surface phase of PLGA scaffolds for sustained release (36). It was observed that sustained release of dexamethasone effectively induced differentiation of bone marrow stem cells to osteoblasts or chondrocytes (37). 
In the present work, polystyrenedivinylbenzene macroporous solid foams were prepared from highly concentrated emulsions by the PIT method, and characterized by different techniques. The novelty of the present study lays on evaluating the influence of the porous structure, surface area and other characteristics, derived from the emulsion-template used, on the release of drugs. Ketoprofen, a potent nonsteroidal anti-inflammatory drug (NSAID), has been widely used for the treatment of rheumatoid arthritis and related diseases (38). However, it accompanies adverse side effects including gastrointestinal irritation when administered orally. Since ketoprofen is usually given to patients over an extended period, efforts to reduce its adverse side effects have been attempted, so new forms are of interest in this field. Thus, the polymers were selected for their inertness towards a lipophilic model drug, to eliminate other possible interactions. Similar structures could constitute dosage forms, so the incorporation of ketoprofen to the synthesised solid foams requires specific study.

\section{MATERIALS AND METHODS}

\section{Materials}

All surfactants, hexaethylene glycol $n$-hexadecyl ether, octaethylene glycol n-dodecyl ether, abbreviated as $\mathrm{C}_{16}(\mathrm{OE})_{6}$ and $\mathrm{C}_{12}(\mathrm{EO})_{8}$, respectively, (Nikko Chemicals Co., Japan) and Synperonic L64 (ICI, Belgium) were used without further purification. Styrene and divinylbenzene (Merck), abbreviated respectively as $\mathrm{S}$ and DVB, were purified by elution through neutral chromatographic aluminum oxide, to eliminate the inhibitor, which is a nonvolatile polar compound. Initiator potassium persulfate 99\% (Fluka), as well as tetradecane 99\% (Merck), were used as received.

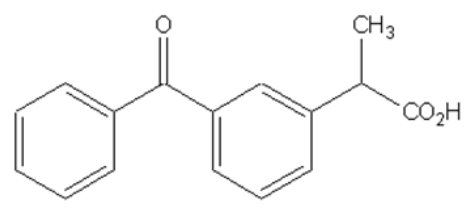

Figure 1. Molecular structure of ketoprofen

Ketoprofen 99.8\% (2-(3-benzoylphenyl)propanoic acid) (Fagron, Spain), was used as model lipophilic molecule for drug delivery (Fig. 1). Phosphate buffer solution (PBS) $(\mathrm{pH}=7.4)$ was prepared from sodium phosphate, potassium phosphate and sodium chloride, all purchased from Merck. The dialysis bags were porous cellulose membranes (Orange Scientific) with a molecular weight cut off (MWCO) of 1200014000 , which allows dialysis of ketoprofen.

\section{Preparation of the solid foams}

\section{Highly Concentrated Emulsions}

The emulsions were prepared from the system $\mathrm{H}_{2} \mathrm{O} / \mathrm{K}_{2} \mathrm{~S}_{2} \mathrm{O}_{8} / \mathrm{C}_{16}(\mathrm{EO})_{6} / \mathrm{C}_{12}(\mathrm{EO})_{8} /$ Synperonic L-64 / styrene / divinylbenzene / tetradecane (89.9/0.1/1.2/0.7/0.1/4.0/1.0/3.0 wt \%), which was prepared as described in the literature (25). Samples were weighted into glass tubes. The emulsions had a weight fraction of the disperse phase equal to 0.9 and were prepared by first cooling to $0{ }^{\circ} \mathrm{C}$. They were vibromixer stirred, and temperature was quickly increased to $60{ }^{\circ} \mathrm{C}$ by placing the samples into a water bath of such temperature, with constant vibromixer agitation, finishing with manual agitation to help phase inversion.

\section{Polymerization}

Solid PS-DVB foams were prepared by reactions in the continuous phase of highly concentrated $\mathrm{W} / \mathrm{O}$ emulsions. The emulsions were kept in sealed glass tubes at $60{ }^{\circ} \mathrm{C}$ for $48 \mathrm{~h}$, allowing polymerization to take place. The wet polystyrene monoliths were then removed by carefully breaking the glass containers. These monoliths were handled cautiously as they were very fragile at this stage. The monoliths were dried at ambient temperature, and were then carefully sliced with a sharp rotary blade into 1-2 mm cylinders of 25 $\mathrm{mm}$ diameter. They were washed firstly with water and secondly with ethanol, at $60^{\circ} \mathrm{C}$ with a solvent volume at least 10 times higher than the sample volume, and then Soxhlet extracted with ethanol to ensure the removal of all the products but polystyrene. Finally, samples were dried by placing them into an oven at $70{ }^{\circ} \mathrm{C}$, until weight was constant.

\section{Milling of the samples}

The solid PS-DVB cylinders (disks) were ground with a rotary ball mill Mixer Mill MM 200 (Retsch) with two $7.15 \mathrm{~g}$ stainless steel balls and a ball to powder ratio of 15 , at $250 \mathrm{rpm}$ for $3 \mathrm{~min}$.

\section{Scanning Electron Microscopy}

Topography of the samples was studied by using a Hitachi S-4100 Field Emission Scanning Electron Microscope (SEM). Previous to 
observation, samples were carbon coated by sputtering.

\section{Determination of specific surface area, total mesopore volume and pore size by Nitrogen sorption}

The nitrogen isotherms were obtained at $77 \mathrm{~K}$ using a Micromeritics, Tristar 3000 apparatus. The total mesopore volume, corresponding to the volume of pores smaller than $\approx 200 \mathrm{~nm}$, was obtained from the isotherms at 0.99 partial pressure. The specific surface area was determined from the adsorption isotherm by applying the BET theory (39) to the low pressure region, where the volume of a $\mathrm{N}_{2}$ adsorbed monolayer $\mathrm{V}_{\mathrm{m}}$, is calculated by linear fitting of equation [1].

$$
\frac{1}{V\left[\left(\frac{P_{0}}{P}\right)-1\right]}=\frac{c-1}{V_{m}}\left(\frac{P}{P_{0}}\right)+\frac{1}{V_{m} c}
$$

where $\mathrm{P}$ and $\mathrm{P}_{0}$ are respectively the equilibrium and the saturation pressure of adsorbate (i.e. $\mathrm{N}_{2}$ ), $\mathrm{V}$ is the adsorbed volume, and $\mathrm{c}$ is the BET constant related to the difference between the energy of adsorption and the energy of liquefaction. The specific surface area, generally denoted as $\mathrm{S}_{\mathrm{BET}}$, can be calculated from $\mathrm{V}_{\mathrm{m}}$ and the cross-section area of a $\mathrm{N}_{2}$ molecule.

The pore size distribution was obtained by using the BJH method (40) applied to the desorption curves. This method is based on Kelvin equation [eq. 2], that estimates the pressure at which the adsorbate will evaporate from a cylindrical pore of a given size. This allows to calculate the pore size from the desorption isotherm.

$$
\ln \left(\frac{\mathrm{P}^{*}}{\mathrm{P}_{0}}\right)=-\left(\frac{2 \gamma v \cos \theta}{\mathrm{RTr}_{\mathrm{m}}}\right)
$$

where $\mathrm{P}^{*}$ is the critical condensation pressure, $\gamma$ the liquid surface tension, $v$ the molar volume of the condensed adsorbate, $\theta$ the contact angle between the solid and condensed phase (taken to be zero when the adsorbate is nitrogen, hence cos $\theta=1), r_{m}$ the mean radius of curvature of the liquid meniscus, $\mathrm{R}$ is the universal gas constant and $\mathrm{T}$ the absolute temperature.

\section{Drug loading}

Ketoprofen was incorporated into the PS-DVB porous materials from solutions in $\mathrm{EtOH} / \mathrm{H}_{2} \mathrm{O}$ 1:1 $\mathrm{w} / \mathrm{w}$, either by slow droplet addition or by immersion of the samples in the drug solution. Solvent was evaporated at $50^{\circ} \mathrm{C}$ for $24 \mathrm{~h}$ until weight was constant.

\section{Drug delivery experiments}

The diffusion experiments were carried out according to previous works (41). Samples were placed in dialysis bags, which were filled with phosphate buffer solution (PBS) and submerged in diffusion cells containing $150 \mathrm{ml}$ of PBS. The diffusion cells consisted on a cylindrical thermojacketed amber glass vessel connected to a water bath at fixed temperature $\left(37^{\circ} \mathrm{C}\right)$ and closed to avoid loss of receptor solution due to evaporation. The receptor solutions were stirred by means of a magnetic stirrer.

Periodically, samples $(1 \mathrm{~mL})$ were withdrawn for determination of ketoprofen concentration by UV spectrophotometry $(\lambda=233 \mathrm{~nm})$. In order to maintain constant the volume of the receptor solution, $1 \mathrm{~mL}$ of fresh PBS solution was added to the receptor bath after each withdrawal. This small dilution effect was taken into account in the calculations of the $\%$ released.

The solubility of ketoprofen in PBS at $\mathrm{pH}=7.4$, as used in this study, is $0.4 \%$. Prior to the experiments, it was calculated that even if the total of ketoprofen present in the solid foams was completely released, still in that case, and considering the volume of the release media, the ketoprofen dissolved would be below the $20 \%$ of its maximum solubility in PBS. Therefore, sink conditions were ensured in these experiments.

At least four replicates have been studied in each case. The experimental error has been calculated as the standard deviation. Statistical differences were determined using one-way ANOVA with Tukey's post-tests using Minitab 16 software (Minitab, Inc., US). Statistical significance was noted when $\mathrm{p}<0.05$.

\section{RESULTS}

As shown by SEM (Fig. 2), the PS-DVB materials studied in this work contain polydisperse macropores, preserving the structure of the continuous phase of the emulsion which served as template for polymerization (Fig. 2a). Such macropores are interconnected by holes of smaller diameter. For the drug delivery experiments, samples of $25 \mathrm{~mm}$ diameter, 
have been sliced into disks of $1-2 \mathrm{~mm}$ thickness. In that case, two surfaces with different topography can be clearly distinguished; that of the inner surface, already described and shown in Fig. 2a, and that of the skin layer, shown in Fig. $2 \mathrm{~b}$.

Macropores of the solid foam disks are in the range of $5-10 \mu \mathrm{m}$, being the largest macropores around $30 \mu \mathrm{m}$, and the smallest around $600 \mathrm{~nm}$.
The possible presence of mesopores $(0.2-50 \mathrm{~nm})$ was evaluated through Nitrogen sorption experiments (Fig. 3). The volume of mesopores is relatively low (the single point method provided a mesopore volume of $0.25 \mathrm{~cm}^{3} / \mathrm{g}$ for the disks, indicated in Table 1), and much smaller than the total pore volume of the solid foam materials $\left.\approx 20 \mathrm{~cm}^{3} / \mathrm{g}^{-1}\right)(42)$.

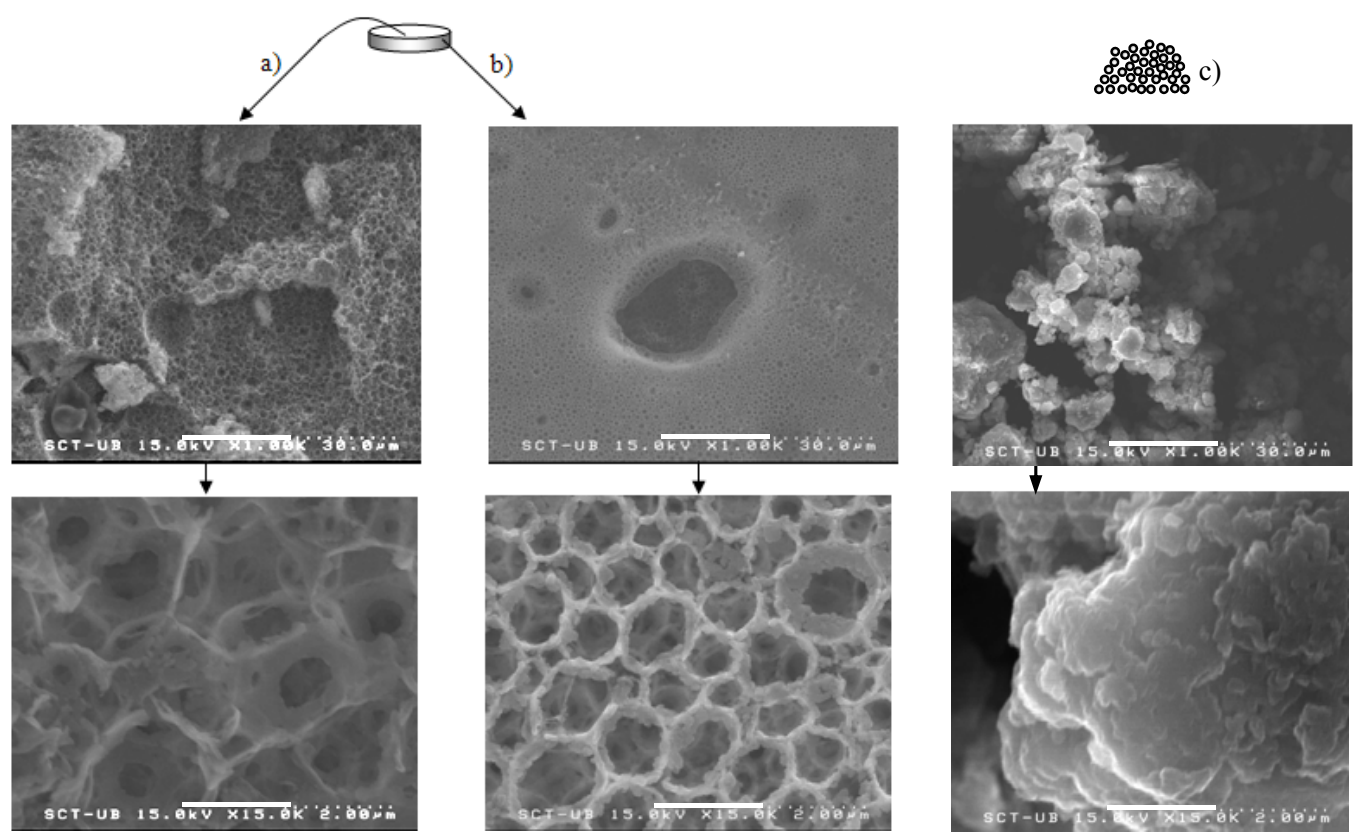

Figure 2. Micrographs of the polystyrene solid foams: (a) inner surface region, (b) skin layer polymerized in contact with the container walls and (c) powders obtained from the ground solid foams.

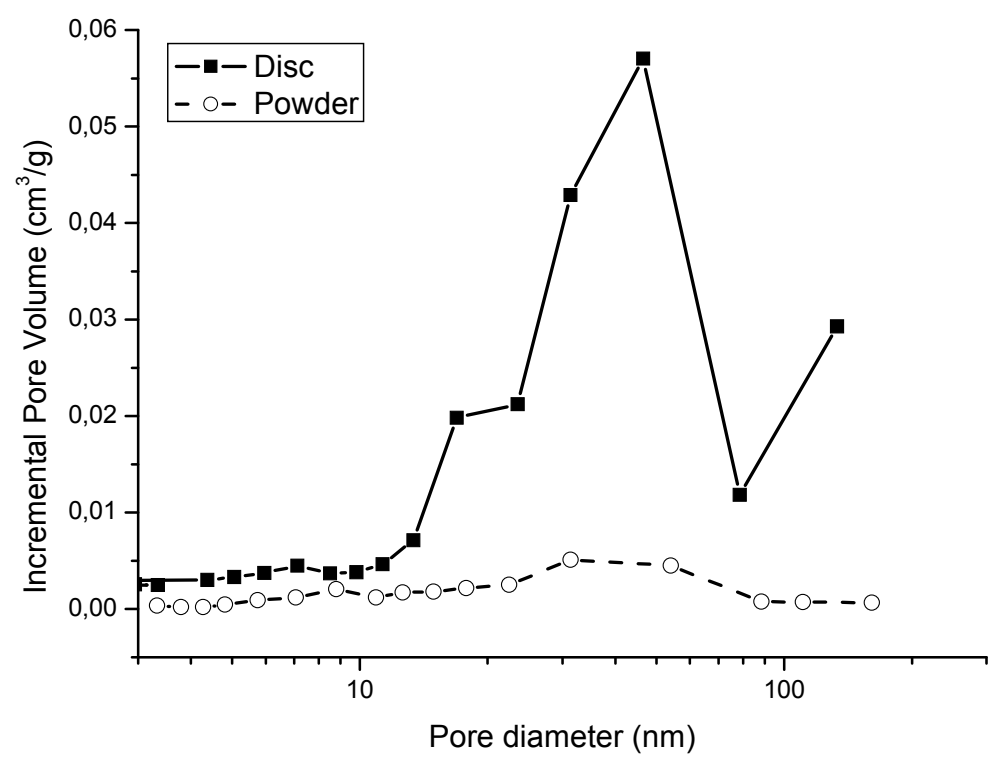

Figure 3. Mesopore size distribution depending on the form (disc or powder) of the solid foams, calculated from the desorption curve by applying the BJH model. 
In order to prepare another material form, the solid foam materials were ground to powder with a rotary ball mill. The grinding process to obtain powders from the materials has not only strongly affected the macropores, as shown by SEM (Fig. 2c), but also the mesopores. This can be seen through the great reduction in surface area from $80 \mathrm{~m}^{2} / \mathrm{g}$, of PS-DVB solid foam disks, to $4 \mathrm{~m}^{2} / \mathrm{g}$ of PS-DVB powders (Table 1). The volume of mesopores determined by Nitrogen sorption experiments, already small, is also considerably reduced.

Impregnation (Table 2) is the critical point of the drug incorporation process since the size and shape of the solid foam form will determine the amount of drug loaded into the material. Two impregnation methods were evaluated: a) droplet addition of the drug containing solution to the materials, or b) immersion of the materials in the drug containing solution. It was observed (Table 2) that weight uptake does not depend much on impregnation method. The results are not statistically different, since the small differences are within the experimental error.

The difficulties with impregnation lead to discard the materials in powder form. With solid foam disks, the droplet addition method did not allow uniform imbibing throughout the disk, which resulted in higher dispersion in the ketoprofen loaded to and released from the solid foam disks. However, the ketoprofen loaded to and released from solid foam disks using the immersion method provided results of the same order of magnitude and lower dispersion values, which indicates the suitability of the method.

Weight uptake of the solid foam disks, impregnated by immersion with ketoprofen solutions of varying concentration, increases progressively with increasing ketoprofen concentration in the solution, as shown in Fig. 4, with values ranging from 26 to $68 \mathrm{wt} \%$ weight uptake in solutions containing from 2 to $10 \mathrm{wt} \%$ ketoprofen, respectively. Therefore, one can conclude that drug uptake is highly dependent on ketoprofen concentration, with statistically different values, since the weight increase is much higher than the experimental error.

Figure 5 shows the drug delivery results of solid foam disks impregnated from the three different ketoprofen concentrations loaded onto the materials, and from a $2 \mathrm{wt} \%$ PBS solution, to compare the influence of the material structure. Burst release, close to $100 \%$ in only $3 \mathrm{~h}$, was registered for the $2 \%$ ketoprofen solution (indicated as * in Fig. 5), while slower kinetics were observed for the solid foam disks, which did not reach the stationary stage within the first $24 \mathrm{~h}$ (indicated as $*^{*}$ in Fig. 5). Maximum release around $80 \%$ was observed after $24 \mathrm{~h}$, with no significant differences among the three differently loaded solid foams.

\begin{tabular}{|c|c|c|c|}
\hline & $\begin{array}{c}\text { Total pore volume } \\
(\mathrm{mL} / \mathrm{g})\end{array}$ & $\begin{array}{c}\text { Mesopore volume } \\
\left(\mathrm{cm}^{3} / \mathrm{g}\right)\end{array}$ & Surface area $\left(\mathrm{m}^{2} / \mathrm{g}\right)$ \\
\hline Disks & $20.5 \pm 0.8$ & 0.25 & 80 \\
\hline Powders & Not determined & 0.03 & 4 \\
\hline
\end{tabular}

Table 2. Drug loaded from a $2 \%$ ketoprofen EtOH/ $\mathrm{H}_{2} \mathrm{O}$ solution and released to a PBS solution PS-DVB disks with different impregnation methods

\begin{tabular}{cccc}
\hline Form & Impregnation method & $\begin{array}{c}\text { \% ketoprofen } \\
\text { loaded (w/w) }\end{array}$ & $\begin{array}{c}\text { \% ketoprofen released after } \\
\mathbf{2 4 h}\end{array}$ \\
\hline Solid foam disk & Droplet addition & $25 \pm 10$ & $70 \pm 17$ \\
Solid foam disk & Immersion & $26 \pm 1$ & $79 \pm 4$ \\
\hline
\end{tabular}




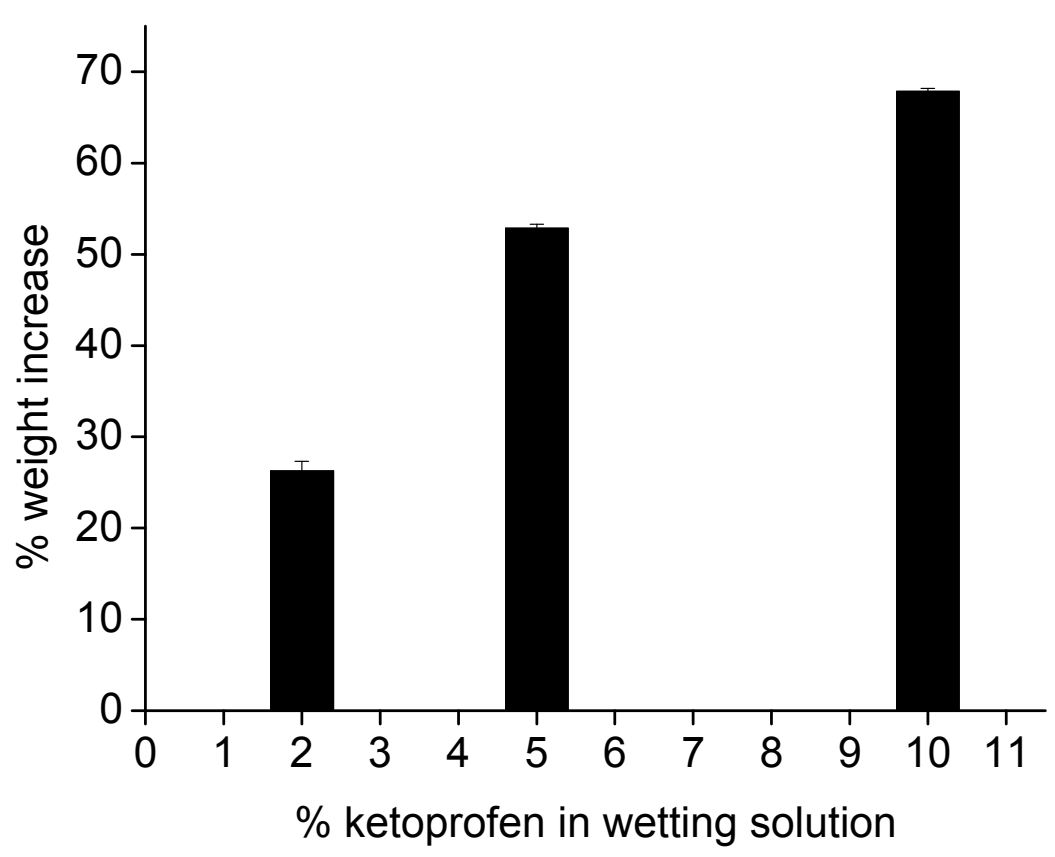

Figure 4. Ketoprofen uptake by the solid foam disks (in weight \%) as a function of the \% ketoprofen in the impregnating EtOH/ $\mathrm{H}_{2} \mathrm{O}$ solution by the immersion method. The error bars indicate the standard deviation.

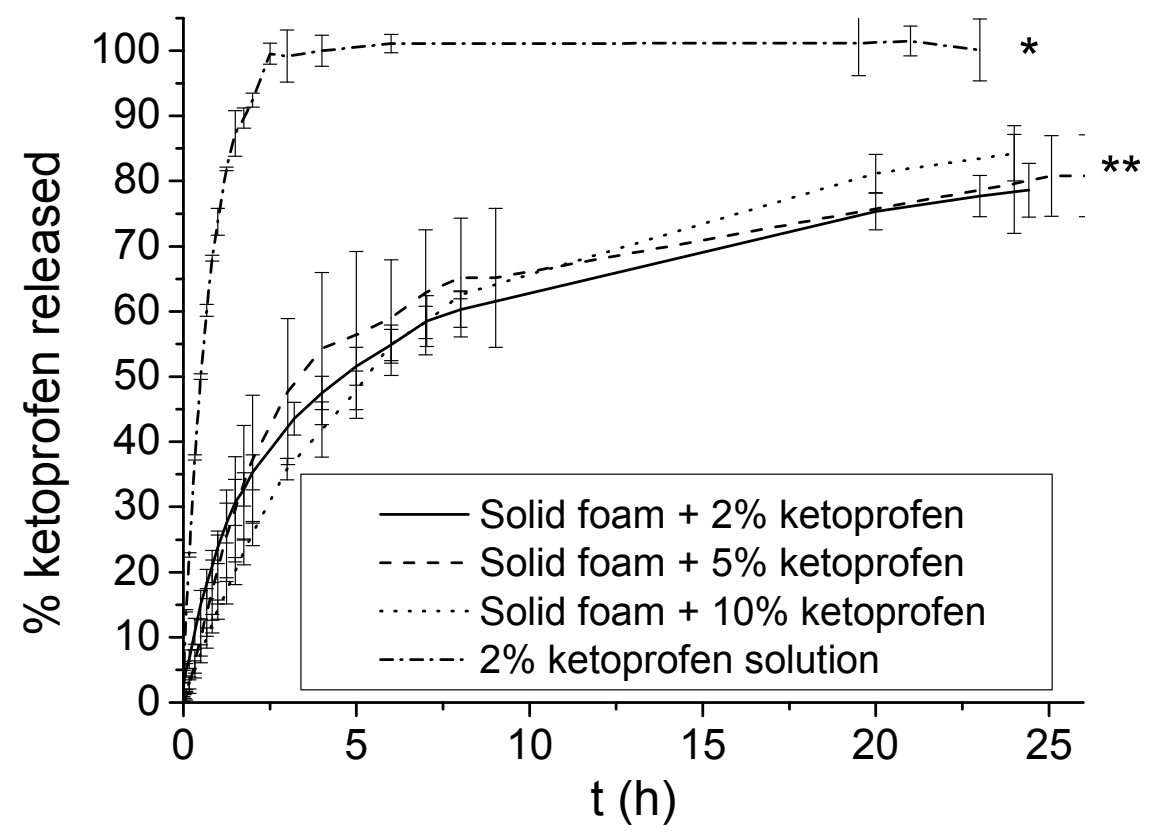

Figure 5. Ketoprofen released from solid foam discs impregnated by immersion in EtOH/ $\mathrm{H}_{2} \mathrm{O}$ solutions $(1: 1 \mathrm{w} / \mathrm{w})$ containing three different ketoprofen concentrations: $2 \%, 5 \%$ and $10 \%$, and comparison with a $2 \% \mathrm{EtOH} / \mathrm{H}_{2} \mathrm{O}$ solution. $(*)$ and $(* *)$ indicate the results from the control solution and from the foam disks, respectively. 


\section{DISCUSSION}

The present work characterizes and evaluates polystyrene-divinylbenzene macroporous materials (solid foams) as possible new vehicles for drug delivery. The solid foams obtained from the highly concentrated emulsions by the PIT method were, in the first place, characterized. Two monomers were present in the emulsion, styrene (S) and divinylbenzene (DVB), which reacted to form styrene-divinylbenzene (PS-DVB) copolymer, with DVB acting as crosslinking agent, which leads to solid foams with interconnected polydisperse macropores (Fig. 2a), according to the template set by the continuous phase of the emulsion. The phase inversion temperature method used for emulsification allowed obtaining the required pore interconnectivity, with views on allowing diffusion of drugs and flow of body fluids through the material. The highly concentrated emulsion has high volume of disperse phase and in that case, droplets are closely packed. Consequently, during polymerization of the continuous phase, in the regions where the continuous phase layer is too thin, a "hole" is formed between two pores thus producing the desired interconnectivity.

SEM images reveal a different structure depending on the region (inner surface and skin layer) of the sample, with lower roughness on the skin layer with respect to the inner surface of the samples. The presence of a smooth skin layer can be explained by the contact with the glass surface of test tubes used as reactors (Fig. 2b), as observed in previous studies $(42,43)$.

Most of the pore volume of the solid foams is due to macropores, with a very small contribution of mesopores (approximately 99\% of the pore volume is located in the macropores, estimated from the mesopore volume and the total pore volume resulting from the density). The small fraction of mesopores found in the materials, has a peak at $40 \mathrm{~nm}$, in the pore size distribution calculated using BJH equations. This is consistent with the fact that the specific surface area $(\approx 80$ $\mathrm{m}^{2} / \mathrm{g}$ ) obtained is significantly smaller than typical mesoporous materials (44).

The morphology of the materials is similar to that determined in previous works (42), although the surface area of the solid foam disks studied here is higher (nearly twofold) than that of monoliths with larger macropore size and higher polydispersity, as it is a parameter which is closely related with the structure of the materials.
Grinding the materials to obtain a powder, which could be used as another form for drug delivery (PS-DVB powders), eliminated both the macropores, and the mesopores (Figs. 2c and 3). The grinding treatment produced a $95 \%$ reduction of the surface area with respect to the PS-DVB solid foam disks (Table 1). Obviously, this reduction in surface area and pore volume is due to a collapse of the porous structure of the materials during the grinding process.

In addition to the morphological properties of the materials, their wetting properties are also of great relevance with views on incorporation and release of active principles. Conventional polystyrene films are hydrophobic with mean contact angle values of $103 \pm 6^{\circ}$ (43), but the particular characteristics of the material used in this work, with very high roughness (Fig. 2a) revealed highly hydrophobic properties (42). In general, materials with rough surfaces show higher contact angles than their smooth homologues. In previous studies it was observed that the inner surface follows the Cassie-Baxter behaviour $(43,45)$, and the measurement of advancing contact angle on the rough surface of the inner surface of the solid foam disks revealed a water contact angle of $143 \pm 13^{\circ}$. Such high value, very close to superhydrophobic surfaces (46) comes from the combination of hydrophobic interactions and high roughness. The materials are thus mainly macroporous with interconnected pores, with high specific surface and highly hydrophobic wetting properties.

Such hydrophobic surface is not wetted by water and would therefore impair incorporation of an active principle such as ketoprofen, to the foams from an aqueous solution. In addition, the measured solubility of ketoprofen in water is very low $(0.014 \%)$, but it is freely soluble in ethanol. Therefore, a hydroalcoholic ketoprofen solution, which achieved good wetting of the samples due to its lower surface tension $(\gamma=28.8 \mathrm{mN} / \mathrm{m})$ than plain water $(\gamma=72.8 \mathrm{mN} / \mathrm{m})$, was used for the impregnation of the PS-DVB solid foam disks. As shown in Fig. 2, and also in accordance to previous papers (25), the pores of the material are interconnected, allowing a flow of the active principle solution throughout the solid foam disk sample.

Taking into account the relatively small size of the ketoprofen molecule (see Fig. 1) (assuming extended conformation, a maximum length of approx. $1.48 \mathrm{~nm}$ can be calculated), it can be assumed that it may penetrate the mesopores present in the sample, particularly considering 
that most mesopores in the solid foam disks are in the range of $10-50 \mathrm{~nm}$ diameter. This is of relevance with views on the incorporation (impregnation) of ketoprofen to the materials, which was carried out either by droplet addition of the drug solution on the materials or by their immersion in the drug solution. The most homogeneous results in the drug incorporation were obtained by immersing the solid foam disks in a solution with the drug, so this method was selected for further experiments.

The net weight of ketoprofen incorporated to the materials from the three solutions studied ( 2 to $10 \mathrm{wt} \%$ ) varies from around $30 \mathrm{mg}$ to $60 \mathrm{mg}$, respectively (Fig.4). Oral and rectal commercial forms usually contain between 50 and $200 \mathrm{mg}$ of ketoprofen, so the new materials studied in the present work allow incorporating sufficient amount of active principle.

In materials aimed for implantation with macroporous structures as the one shown, advantages of macroporosity come in two directions: In the first place, the interconnectivity between pores enhances water penetration and the shorter diffusion path in the polymer increases the release rate of hydrophobic molecules. This was observed by Lee et al. for Paclitaxel loaded Polylactide-co-glycolide foams (47). In the second place, the existence of macropores in the material promote bulk resorption of the implant (in case of biodegradable materials) (48) and favour cell colonisation and tissue ingrowth, thus promoting its integration within the host body. Previous works comparing drug release from biodegradable dense polymers or from their foamed analogues found enhanced drug delivery from the macroporous foams (47).

Considering the pore size distribution of the sample in two main groups, mesopores and macropores, it could be speculated that the release kinetics of active principle incorporated to the solid would take place in two steps; a faster one corresponding to the release from the macropores, more accessible, and a slower one corresponding to the release from the mesopores, in which the "way out" of the active principle is longer (following the same principle as in exclusion chromatography resins). However, the potential contribution of mesopores to the ketoprofen release kinetics from the solid foams (Fig. 5) is not obvious, and that could be related to the small percentage of these lower-range pores.

Release kinetics from the PS-DVB solid foams was found to be independent of the amount of drug loaded into the material in the range of 2-
$10 \mathrm{wt} \%$ studied, with a final release (after $24 \mathrm{~h}$ ) of $80 \%$ in all cases. Comparison of the release curves from the $2 \mathrm{wt} \%$ impregnated solid foam disks with the release from a solution containing the same amount of ketoprofen than the material clearly shows that the studied materials achieve a delayed release of the studied active principle. It must also be underlined that the release from the solid foams did not reach the stationary stage after $24 \mathrm{~h}$, reflecting potential for release of the entire drug.

This can possibly be attributed, among other factors, to the contribution of the interconnected macroporosity to the fluid penetration throughout the bulk of the material, thus facilitating drug release. Such results indicate that the particular features of the 3D interconnected porous structure of the solid foams studied are relevant towards a controlled release of active principles. Therefore, in-vitro release of the lipophilic model drug studied from PS-DVB solid foams was efficient with a short lag-time and delayed release of the drug was achieved, suggesting a potentially useful pharmaceutical application of materials with similar morphology prepared from highly concentrated emulsions.

\section{ACKNOWLEDGEMENTS}

The authors acknowledge financial support of MCYT within the project CTQ 2008-06892C03/PPQ, and the support of Departament d'Educació i Universitats of Generalitat de Catalunya for the post-doc fellowship of C.C.

\section{REFERENCES}

1. Attwood E. Disperse systems in Pharmaceutics, the science of dosage form design, $2^{\text {nd }}$ Ed. Aulton ME. Ed. Churchill Livingstone, Elsevier, 2002.

2. Arzhavitina A., Steckel H. Foams for pharmaceutical and cosmetic application International Journal of Pharmaceutics 394: 1-17, 2010.

3. Perut F, Montufar EB, Ciapetti G, Santin M, Salvage J, Traykova T, Planell JA, Ginebra MP, Baldini N. Novel soybean/gelatine-based bioactive and injectable hydroxyapatite foam: Material properties and cell response, Acta Biomaterialia 7:1780-1787, 2011.

4. O'Brien FJ, Harley BA, Waller MA, Yannas IV, Gibson LJ, Prendergast PJ. The effect of pore size on permeability and cell attachment in collagen scaffolds for tissue engineering. Technol Health Care 15(1):3-17, 2007. 
5. Karageorgiou V, Kaplan D. Porosity of 3D biomaterial scaffolds and osteogenesis. Biomaterials 26:5474-91, 2005.

6. Raucci MG, D’Antò V, Guarino V, Sardella E, Zeppetelli S, Favia P, et al. Biomineralized porous composite scaffolds prepared by chemical synthesis for bone tissue regeneration. Acta Biomater 6:4090-9, 2010.

7. Kim HW, Knowles JC, Kim HE. Hydroxyapatite/poly([epsilon]-caprolactone) composite coatings on hydroxyapatite porous bone scaffold for drug delivery. Biomaterials 25:127987, 2004.

8. Hedberg EL, Shih CK, Lemoine JJ, Timmer MD, Liebschner MAK, Jansen JA. In vitro degradation of porous poly(propylene fumarate)/poly(DLlactic-coglycolic acid) composite scaffolds. Biomaterials 26:3215-25, 2005.

9. Pek YS, Gao S, Mohamed Arshad MS, Leck K-J, Ying JY. Porous collagen-apatite nanocomposite foams as bone regeneration scaffolds. Biomaterials 29:4300-4305, 2008.

10. Diamond NG, Casarella WJ, Bachman DM, Wolff M. Microfibrillar collagen hemostat: a new transcatheter embolization agent. Radiology 133:775-779, 1979.

11. Yannas IV, Burke JF, Warpehoski M, Stasikelis P, Skrabut EM, Orgill D, Giard DJ. Prompt, longterm functional replacement of skin. Trans Am Soc Artif Intern Organs 27:19-22, 1981.

12. Doillon CJ, Silver FH, Berg RA. Fibroblast growth on a porous collagen sponge containing hyaluronic acid and fibronectin. Biomaterials 8:195-200, 1987.

13. Grenga $\mathrm{T}$, Zins JE, Bauer TW. The rate of vascularization of coralline hydroxyapatite. Plas. Reconstr. Surg. 84:245-249, 1989.

14. Liao SS, Cui FZ, Zhang W, Feng QL. Hierarchically biomimetic bone scaffold materials: nano-HA/collagen/PLA composite. J Biomed Mater Res 69B:158-165, 2004.

15. Schliephake H, Neukam FW, Klosa D. Influence of pore dimensions on bone ingrowth into porous hydroxyapatite blocks used as bone substitutes. A histometric study. J Oral Maxillofac Surg 20:53$58,1991$.

16. Tancred DC, McCormack BAO, Carr AJ. A synthetic bone implant macroscopically identical to cancellous bone. Biomaterials 19:2303-2311, 1998.

17. Sher P, Ingavle G, Ponrathnam S, Pawar AP. Low density porous carrier based conceptual drug delivery system. Microp. Mesop. Mat., 102:290298, 2007.

18. Sant S, Nadeau V, Hildgen P. Effect of porosity on the release kinetics of propafenone-loaded PEG-g-PLA nanoparticles. J. Control Release, 107:203-214, 2005.

19. Hartmann M. Ordered Mesoporous Materials for Bioadsorption and Biocatalysis, Chem. Mater., 17:4577-4593, 2005.
20. Yiu HHP, Wright PA. Enzymes supported on ordered mesoporous solids: a special case of an inorganic-organic hybrid. J. Mater. Chem., 15:3690-3700, 2005.

21. Wang S. Ordered mesoporous materials for drug delivery. Microporous and Mesoporous Mat., 117:1-9, 2009.

22. Song SW, Hidajat K, Kawi S. Functionalized SBA-15 Materials as Carriers for Controlled Drug Delivery: Influence of Surface Properties on Matrix- Drug Interactions. Langmuir, 21:95689575, 2005.

23. Ruckenstein E. Concentrated emulsion polymerization. Adv. Polym. Sci., 127:1-58, 1997.

24. Ciesla U, Schüth F. Ordered mesoporous materials. Microp. Mesop. Mat., 27(2-3):131-149, 1999.

25. Esquena J, Sankar GSRR, Solans C. Highly concentrated W/O emulsions prepared by the PIT method as templates for solid foams. Langmuir, 19:2983-2988, 2003.

26. Kaemmerlen A, Vo C, Asllanaj F, Jeandel G, Baillis D. Radiative properties of extruded polystyrene foams: Predictive model and experimental results J. Quantitative Spectroscopy \& Radiative Transfer 111: 865-877, 2010.

27. J.R. Memon JR, Pathan AG. Efficiency of Cd(II) removal from aqueous media by using chemically modified polystyrene foam. European Polymer J. 44: 1501-1511, 2008.

28. Esquena J, Solans C., Highly Concentrated Emulsions as Templates for Solid Foams, in: J. Sjöblom, ed. Emulsions and Emulsion Stability. New York: Taylor and Francis, 2006.

29. Williams JM, Wrobleski DA. Spatial distribution of the phases in water-in-oil emulsions. Open and closed microcellular foams from cross-linked polystyrene. Langmuir, 4: 4062-4067, 1988.

30. Barby D, Haq Z. Eur. Patent 0060138, 1982.

31. Kunieda H, Shinoda K. Evaluation of the hydrophile-lipophile balance (HLB) of nonionic surfactants. I. Multisurfactant systems. J. Colloid Interface Sci., 107:107-121, 1985.

32. Kunieda H, Fukui Y, Uchiyama H, Solans C. Spontaneous formation of highly concentrated water-in-oil emulsions (gel-emulsions). Langmuir 12: 2136-2140, 1996.

33. Ozawa K, Solans C, Kunieda H. Spontaneous formation of Highly Concentrated Water-in-oil emulsions. J. Colloid Interface Sci. 188:275-281, 1997.

34. Solans C, Pons R, Kunieda H. In Modern Aspects of Emulsion Science; Binks BP Ed. Royal Society of Chemistry: Cambridge, U.K., 367-394, 1998.

35. Ensing GT. Prevention and treatment of biomaterial related infection in orthopedics: a study of application of ultrasound and of antibiotic release. PhD Thesis, Rijksuniversiteit Groningen 2006.

36. Yoon JJ, Kim JH, Park TG. Dexamethasone releasing biodegradable polymer scaffolds 
fabricated by a gas foaming/salt leaching method. Biomaterials, 24:2323-2329, 2003.

37. Chen J, Wang C, Lu S, Wu J, Guo X, Duan C, Dong L, Song Y, Zhang J, Jing D, Wu L, Ding J, $\mathrm{Li} \mathrm{D}$. In vivo chondrogenesis of adult bonemarrow-derived autologous mesenchymal stem cells. Cell Tissue Res., 319:429-438, 2005.

38. Kantor TG. Ketoprofen: a review of its pharmacologic and clinical properties. Pharmacotherapy, 6(3): 93-103, 1986.

39. Brunauer S, Emmett PH, Teller E. Adsorption of gases in multimolecular layers J. Am. Chem. Soc. 60: 309-315, 1938.

40. Barret EP, Joyner JG, Halenda PP. The determination of pore volume and Area distributions in porous substances I. Computations from Nitrogen Isotherms J. Am. Chem. Soc. 73: 373-380, 1951.

41. Calderó G, García-Celma MJ, Solans C, Plaza M, Pons R, Influence of Composition Variables on the Molecular Diffusion from Highly Concentrated Water-in-Oil Emulsions (GelEmulsions). Langmuir, 13:385-390, 1997.

42. Canal C, Gaboriau F, Vílchez A, Erra P, GarcíaCelma MJ, Esquena J. Topographical and
Wettability Effects of Post-Discharge Plasma Treatments on Macroporous PolystyreneDivinylbenzene Solid Foams. Plasma Process. Polym,6(10):686-692, 2009.

43. Molina R, Vílchez A, Canal C, Esquena J. Wetting properties of polystyrene/divinylbenzene crosslinked porous polymers obtained using $\mathrm{W} / \mathrm{O}$ highly concentrated emulsions as templates. Surf. Interface Anal., 41(5):371-377, 2009.

44. Esquena J, Rodriguez C, Solans C, Kunieda H, Formation of mesostructured silica in nonionic fluorinated surfactant systems, Microp. Mesop. Mater., 92:212-219, 2006.

45. Cassie ABD, Baxter S. Wettability of porous surfaces. Trans. Faraday Soc., 40:546-551, 1944.

46. Quéré D. Fakir Droplets. Nat. Mater., 1:14-15, 2002.

47. Lee LY., Ranganath SH, Fu Y, Zheng JL, Lee HS, Wang C-H, Smith KA. Paclitaxel release from micro-porous PLGA disks. Chemical Engineering Science 64: 4341-4349, 2009.

48. Lao LL, Peppas NA, Boey FYC, Venkatraman SS. Modeling of drug release from bulk-degrading polymers International Journal of Pharmaceutics 418: 28-41, 2011. 